\title{
Papiloma en úvula
}

\author{
Eva Buller Viqueira ${ }^{a}$, Juana Cabello Pulido ${ }^{\mathrm{b}}$ y Esperanza Buller Viqueira ${ }^{\mathrm{c}}$
}

aCentro de Salud de Barbate. Barbate. Cádiz (España). ${ }^{\text {b} C e n t r o ~ d e ~ S a l u d ~ d e ~ V e ́ j e r . ~}$ Véjer de la Frontera. Cádiz (España).

'Asistencial Europa Reifs. Chiclana. Cádiz (España).

Correspondencia:

Eva Buller Viqueira. Centro de Salud de Barbate. Avda. del Mar, s/n. C.P. 11160. Barbate (Cádiz). España.

Correo electrónico: miji_77@yahoo.com.

Recibido el 8 de abril de 2015.

Aceptado para su publicación el 15 de junio de 2015.

\section{RESUMEN}

Presentamos el caso de un paciente con sensación de cuerpo extraño en la garganta y finalmente diagnosticado de papiloma invertido y papiloma escamoso de úvula. Tras la cirugía la evolución fue favorable.

PALABRAS CLAVE: Úvula. Infecciones por Papilomavirus. Mucosa Oral.

\section{ABSTRACT}

\section{Uvula papilloma}

The present is a case of a patient with a foreign body sensation in the throat and final diagnosis of inverting papilloma and squamous papilloma of uvula. After surgery, the evolution was successful.

KEY WORDS: Uvula. Papillomavirus Infections. Oral Mucosa.

\section{INTRODUCCIÓN}

Los papilomas son lesiones benignas provocadas por el virus del papiloma humano (VPH), del que existen más de 150 tipos. Estos virus infectan las células epiteliales escamosas tanto de la piel como de las mucosas. Son infecciones que suelen pasar desapercibidas y solo una pequeña proporción resulta en lesiones tanto benignas como precancerosas o cáncer.

Es fundamental el papel del médico de familia en el diagnóstico del papiloma de la mucosa oral. El examen oral convencional que realiza el médico de familia con frecuencia es la base para su diagnóstico. Es fundamental la derivación temprana para su diagnóstico precoz y tratamiento si procede.

\section{CASO CLÍNICO}

Presentamos el caso de un varón de 33 años con antecedentes personales de ansiedad, por lo que sigue tratamiento con escitalopram $10 \mathrm{mg}$ y alprazolam 0,5 mg. Exfumador desde hace 6 meses.

Acude a urgencias de Atención Primaria refiriendo "asfixia", sensación de falta de aire y de cuerpo extraño faríngeo. A la exploración presenta buen murmullo vesicular sin ruidos sobreañadidos, saturación de oxígeno $98 \%$. A la inspección de la faringe presenta una úvula con prolongación filiforme y en su base una lesión papilomatosa engrosada (Figura 1).

Se tranquiliza al paciente y se le explica la patología. Se aconseja valoración por su médico de familia, quien deriva al otorrinolaringólogo (ORL). Se le 


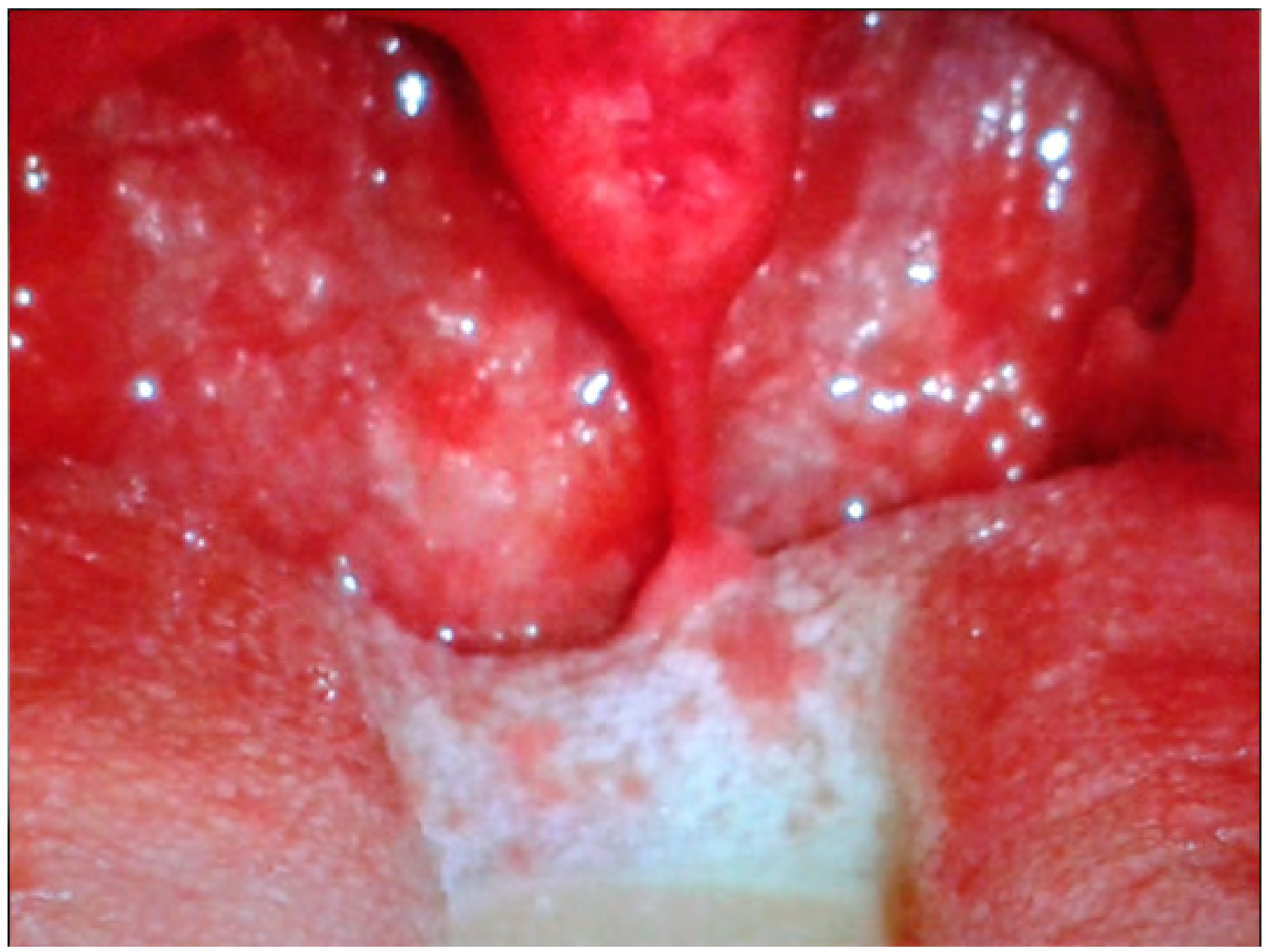

Figura 1. Paciente con úvula filiforme y lesión papilomatosa en su extremo más distal (imagen difícil de captar por el importante reflejo nauseoso del paciente).

realizó cribado de otras patologías de transmisión sexual con resultados negativos para infección por sífilis, virus de inmunodeficiencia humana, herpes $\mathrm{y}$ hepatitis.

El ORL le diagnostica de poliposis senonasal izquierda con remodelación ósea, desviación del tabique nasal, ensanchamiento del infundíbulo del seno maxilar y úvula con formación papilomatosa en su base y engrosamiento de la misma. Se interviene y desde Anatomía Patológica informan de un papiloma invertido en el seno nasal y la lesión en úvula como papiloma escamoso.

Actualmente el paciente ha mejorado notablemente tanto por la sintomatología nasal a la que no hizo referencia hasta llegar al ORL como por la sensación de cuerpo extraño.
En este caso en particular sería interesante poner en conocimiento que el paciente no mantiene buena relación con su médico de familia porque en su opinión no le trata bien su clínica ansioso-depresiva. El paciente suele acudir a consulta cuando su médico esta saliente de guardia o de vacaciones; de hecho el tratamiento antidepresivo y ansiolítico no fue instaurado por su médico, haciendo complicado el seguimiento de su patología. El paciente no comentó nada sobre la congestión que le provocaba la poliposis nasal por el mismo motivo. La relación que tiene con su médico de familia también ayuda a explicar por qué acude a urgencias por una consulta que realmente no es aguda. Tampoco podemos descartar que sus síntomas hayan pasado desapercibidos por los facultativos relacionándolos con la ansiedad. 


\section{DISCUSIÓN}

El papiloma es la lesión epitelial más frecuente en la mucosa oral. La ratio por sexo es de 1,5 hombres por cada mujer afectada y una edad media de 33 años. Con más frecuencia crecen a nivel del paladar, la lengua, el labio superior y la mucosa oral en orden descendente y suelen pasar desapercibidos $^{1,2}$. La clínica depende de la localización: los papilomas en la úvula pueden cursar desde asintomáticos a provocar irritación faríngea, vómitos, dolor, disfagia... ${ }^{1-4}$

Es provocado por el virus del papiloma humano (VPH). En los últimos años se ha observado un aumento en la incidencia de papilomas debido al aumento de enfermedades infectocontagiosas, las relaciones sexuales sin métodos de barrera, el aumento de la promiscuidad y los cambios de hábitos sexuales (aumento de la práctica del sexo orogenital). El $75 \%$ de la población sexualmente activa puede adquirir la infección durante la vida. Otra forma de contagio oral se presenta a consecuencia de la esterilización inadecuada de instrumental médico-quirúrgico durante la exploración endoscópica y oral ${ }^{5,6}$.

El VPH pertenece a un grupo de virus de ADN de doble cadena helicoidal protegido por la cápside, que contiene proteínas de superficie facilitando la fijación del virus a células susceptibles, lo que induce la formación de lesiones hiperplásicas, papilomatosas y verrugosas en piel y mucosas, incluyendo el tracto anogenital, la uretra, la piel, la mucosa traqueobronquial, la cavidad nasal, los senos paranasales, la cavidad bucal, el esófago y la conjuntiva ${ }^{5}$.

A nivel oral crecen con más frecuencia en el paladar, la lengua, el labio superior y la mucosa oral en orden descendente y suelen pasar desapercibidas. Suelen ser masas de no más de $0,5 \mathrm{~cm}$ de tamaño (aunque se han descrito de hasta $3 \mathrm{~cm}$ ), blancas o moradas (según la queratinización de la mucosa), sésiles o pedunculadas, únicas o múltiples, rugosas de bordes pronunciados e irregulares. El aspecto clínico del papiloma escamoso es similar al del carcinoma exofítico, el carcinoma verrugoso y el condiloma acuminado, de ahí la importancia de su reconocimiento y derivación temprana. El $10 \%$ de los cánceres de la cavidad oral son producidos por el $\mathrm{VPH}^{5,6}$.

En cuanto a la prevención primaria de los VPH, lo principal es disminuir los factores de riesgo como el tabaquismo, el abuso de alcohol, la onicofagia, el uso de anticonceptivos orales, la promiscuidad y las relaciones sexuales de riesgo, y favorecer el uso del preservativo masculino y la vacunación, además de llevar a cabo la dieta mediterránea.

Actualmente existen en el mercado 3 tipos de vacunas:

- La bivalente: que contiene partículas similares a virus o virus-like proteins (VLP) del VPH 16 y 18, que son los causantes del $70 \%$ del cáncer de cuello de útero, vulva, vagina, pene, ano y orofaringe. Su nombre comercial

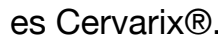

- La tetravalente: que contiene VLP del VPH 16 y 18, además de 6 y 11, que son las responsables del $90 \%$ de las verrugas genitales externas. Su nombre comercial es Gardasilß).

- La nonavalente: que contiene VLP del VPH, $6,11,16$ y 18, además de $31,33,45,52$ y 58. Es responsable de otro $20 \%$ de cáncer de cuello de útero. Su nombre comercial es Gardasil 9®7.

En un estudio publicado en julio de 2013 por la Agencia Internacional de Investigación sobre el Cáncer (AIIC) de la Organización Mundial de la Salud (OMS), realizado en colaboración con investigadores de Costa Rica y el Instituto Nacional de Cáncer de los Estados Unidos, se muestra por primera vez que la vacuna bivalente también provee fuerte protección contra infecciones por VPH asociados con el cáncer de la orofaringe y las amígdalas ${ }^{8}$. El uso de dicha vacuna, orientada a la prevención secundaria o de manera terapéutica, se encuentra aún en fase de investigación clínica.

La prevención secundaria consiste en el diagnóstico precoz que se lleva a cabo principalmente desde Atención Primaria y Odontología con una cuidadosa inspección de la cavidad oral.

La prevención terciaria consta del diagnóstico de las recidivas y del tratamiento de las complicaciones, siendo la de peor pronóstico el cáncer orofaríngeo.

El VPH puede encontrarse en la mucosa oral sin clínica alguna o puede dar lugar a papilomas escamosos, condilomas acuminados, verrugas vulgares, o hiperplasia epitelial focal en el caso del VPH 
$6,11,13$ o 32. También puede generar displasia epitelial o carcinoma oral de células escamosas en caso del VPH 16, 18, 31, 33 o $35^{9}$.

En cuanto al tratamiento del VPH, no se puede erradicar de la mucosa pero sí se pueden eliminar las lesiones, ya sea con crioterapia, láser, cirugía con asa electrónica o cirugía convencional.

En Atención Primaria exploramos constantemente la cavidad oral ya sea por odontalgias, dolor faríngeo o por otras múltiples causas. Ya que estas lesiones son mayoritariamente asintomáticas sería conveniente tenerlas en cuenta a la hora de la exploración. El reconocer la lesión permite el diagnóstico precoz y el posterior tratamiento, previniendo el progreso a lesiones malignas.

También nos parece interesante aprovechar este caso clínico para hacer referencia a los diagnósticos secundarios que se hacen en pacientes con trastorno ansioso-depresivo. Es cierto que la sintomatología de pacientes con ansiedad o depresión es muy amplia, pero es importante siempre hacer un diagnóstico diferencial. Existe tendencia a achacar signos y síntomas de otras patologías a la ansiedad. Suelen ser pacientes hiperfrecuentadores que hacen consultas varias y de motivaciones diversas sin importancia relevante para el médico de familia, pero esto no debe cegar al médico a la hora de hacer otros diagnósticos.

\section{BIBLIOGRAFÍA}

1. Devi RS, Rajsekhar B, Srinivas GV, Moon NJ. Unusual length of pedicle: pedunculated squamous papilloma of uvula cCausing unusual dysphagia of long duration in a child of 10 years. Case Rep Dent. 2014; 2014: 313506.

2. Kulbersh BD, Wiatrak BJ. Pediatric lingual and other intraoral lesions. Otolaryngol Clin North Am. 2015; 48 (1): 175-90.

3. Daghistani KJ. Conditions of the uvula: a 14 years experience. Auris Nasus Larynx. 2000; 27 (3): 261-4.

4. Goodstein LA, Khan A, Pinczewski J, Young VN. Symptomatic squamous papilloma of the uvula: report of a case and review of the literature. Case Rep Otolaryngol. 2012; 2012: 329289.

5. Medina ML, Medina MG, Merino LA. Consideraciones actuales sobre la presencia de papilomavirus humano en la cavidad oral. Av Odontoestomatol. 2010; 26 (2): 71-80.

6. Jaju PP, Suvarna PV, Desai RS. Squamous papilloma: case report and review of literature. Int J Oral Sci. 2010; 2 (4): 222-5.

7. Bruni L, Serrano B, Bosch X, Castellsagué X. Vacuna frente al virus del papiloma humano. Eficacia y seguridad. Enferm Infecc Microbiol Clin 2015; 33 (5): 342-54.

8. Herrero R, Quint W, Hildesheim A, Gonzalez P, Struijk L, Katki HA et al. Reduced prevalence of oral human papillomavirus (HPV) 4 years after bivalent HPV vaccination in a randomized clinical trial in Costa Rica. PloS One 2013; 8 (7): e68329.

9. Vasallo FJ, López-Pintor R, De Arriba L, Hernández G, López AF. Papiloma oral. Cient Dent 2009; 6 (2): 123-5. 